\title{
TGF- $\beta$ orchestrates the phenotype and function of monocytic myeloid-derived suppressor cells in colorectal cancer
}

\author{
Luciana Gneo $^{1} \cdot$ Nagy Rizkalla $^{1} \cdot$ Rahul Hejmadi $^{2} \cdot$ Francis Mussai $^{1} \cdot$ Carmela de Santo $^{1} \cdot$ Gary Middleton $^{1}$ (I)
}

Received: 23 June 2021 / Accepted: 1 October 2021 / Published online: 2 November 2021

(c) The Author(s) 2021

\begin{abstract}
Background Monocytic myeloid-derived suppressor cells (M-MDSCs) are significantly expanded in the blood of colorectal cancer (CRC) patients. However, their presence and underlying mechanisms in the tumour microenvironment of CRC have not been examined in detail.

Methods Tumour tissues and peripheral blood from CRC patients were analysed for the presence of M-MDSCs. The mechanisms of suppression were analysed by blocking pathways by which MDSCs abrogate T cell proliferation. Co-culture of CRC cells with monocytes were performed with and without cytokine blocking antibodies to determine the mechanism by which CRC cells polarise monocytes. Multi-spectral IHC was used to demonstrate the intra-tumoral location of M-MDSCs. Results Tumour tissues and blood of CRC patients contain M-MDSCs which inhibit T cell proliferation. Whilst inhibition of arginase and nitric oxide synthase 2 fail to rescue T cell proliferation, blockade of IL-10 released by these HLA-DR ${ }^{-}$cells abrogates the suppresivity of M-MDSCs. Tumour conditioned media (TCM) significantly reduces HLA-DR expression, increases IL-10 release from monocytes and causes them to become suppressive. TGF- $\beta$ is highly expressed in the TCM and accumulates in the plasma. TGF- $\beta$ reduces HLA-DR expression and drives monocyte immunosuppressivity. The invasive margin of CRC is enriched in $\mathrm{CD} 14^{+} \mathrm{HLA}^{-\mathrm{DR}}{ }^{-}$cells in close proximity to $\mathrm{T}$ cells.

Conclusions Our study demonstrates the cross-talk between CRC cells, M-MDSCs and T cells. Characterisation of CRC M-MDSCs point to therapeutic avenues to target these cells in addition to TGF- $\beta$ blockade.
\end{abstract}

Keywords M-MDSCs $\cdot$ TGF $\beta \cdot \mathrm{IL}-10 \cdot$ Colorectal cancer $\cdot$ pSTAT3

\section{Background}

The identification of a cell as a myeloid-derived suppressor cell (MDSC) requires both the appropriate phenotypic characterisation and evaluation of functional characteristics [1]. In humans three main MDSC phenotypes are recognised: polymorphonuclear MDSCs (PMN-MDSCs: CD15 ${ }^{+}$ CD $11 b^{+} \mathrm{CD} 14^{-}$), monocytic MDSCs (M-MDSCs: CD14 ${ }^{+}$

Luciana Gneo and Nagy Rizkala contributed equally to this article.

Francis Mussai, Carmela De Santo, Gary Middleton are joint senior authors.

Gary Middleton

G.Middleton@bham.ac.uk

1 Institute of Immunology and Immunotherapy, University of Birmingham, Edgbaston, Birmingham B152TT, UK

2 Department of Pathology, University Hospital Birmingham, Birmingham, UK
$\left.\mathrm{CD}_{11 \mathrm{~b}^{+} \mathrm{CD}^{-} 5^{-} \text {HLA-DR }}{ }^{\text {low/- }}\right)$ and early-stage MDSCs (eMDSCs: Lin $^{-}(\mathrm{CD} 3 / 14 / 15 / 19 / 56) \mathrm{HLA}_{-} \mathrm{DR}^{-} \mathrm{CD}^{+} 3^{+}$). Accepted functional verification assays include autologous systems (typically the suppression by the added MDSC populations of CD3/CD28 induced T cell proliferation) and/or allogeneic systems (suppression of proliferation in allogeneic mixed lymphocyte reactions (MLR)).

In the UK alone, there are over 42,000 new cases of colorectal cancer (CRC) per annum and over 16,000 people die of the disease each year making it the second commonest cause of cancer death [2]. The therapy of metastatic proficient mismatch repair CRC has remained largely unchanged in the last 10 years. Whilst checkpoint blockade has become a key therapeutic modality in advanced deficient mismatch repair CRC such therapy has been disappointing in proficient mismatch repair. Whilst antiMDSC strategies have enhanced the efficacy of checkpoint blockade in pre-clinical models [3, 4] whether tumoral MDSCs are important in limiting checkpoint blockade 
efficacy in human CRC is currently unknown. However, an accurate understanding of their biology would be of value in informing the rational design of combinatorial immunotherapy in CRC. Although there are several studies on MDSCs in CRC, many of the studies provide limited data on tumoral MDSCs [5-7] and/or lack functional readouts [8-12]. One study that phenotypically and functionally analysed tumoral MDSCs in CRC focussed exclusively on PMN-MDSCs [13] Accumulation of CD66b + PMNMDSCs appeared to be due to enhanced migration related to IL- 8 and GM-CSF produced by $\gamma \delta \mathrm{T} 17$ cells. However, not all intra-tumoral CD66b + cells in CRC are suppressive; tumour-associated CD66b + neutrophils CRC tissues activate $\mathrm{T}$ cells and stimulate IFN $\gamma$ production [14]. Further, the principal IL-17 producing cells in CRC appear not to be $\gamma \delta \mathrm{T} 17$ but Th 17 cells: $\gamma \delta \mathrm{T}$ cells are mainly IL-17 negative [15].

We decided to focus on M-MDSCs in CRC for a number of reasons besides this conflicting data on tissue $\mathrm{CD} 6 \mathrm{~b}^{+}$cells. Concerns have been raised about the functional impact of the manipulation of dissociated tissue on PMN-MDSCs and the limitations of the commonly used density centrifugation to isolate circulating PMN-MDSC [16, 17]. Some studies in mice have clearly shown that whilst PMN-MDSCs have minimal suppressive effects on antigen stimulated CD8 $+\mathrm{T}$ cells and are non-tolerogenic in vivo, M-MDSCs are highly immunosuppressive $[18,19]$. Furthermore, M-MDSCs appear to be important precursors of suppressive tumour-associated macrophages [20]. Macrophages derived from M-MDSCs have higher amounts of S100A9, nitric oxide synthase 2, ARG1 and much lower HLA-DR expression than those derived from classical monocytes, are polarised toward an M2 phenotype and are highly immunosuppressive. Finally, M-MDSCs appear to be the main immunosuppressive MDSC population in CRC [21]. Whilst M-MDSCs are significantly expanded in the blood of CRC patients the difference in PMN-MDSCs is non-significant. The abundance of M-MDSCs doubled on treatment suggestive of M-MDSCs mediating therapy resistance. Higher M-MDSC levels portend a worse progression free survival to first-line oxaliplatin-based therapy [5]. Whilst peripheral M-MDSCs were shown to suppress proliferation [21] limited mechanistic work was performed and no analysis of intra-tumoral CRC M-MDSCs was undertaken. Here, we demonstrate the mechanism by which CRC cells polarise monocytes to become M-MDSCs and the mechanism by which these cells both in blood and tumour suppress $\mathrm{T}$ cell proliferation, thus significantly advancing our knowledge of M-MDSCs in CRC. Furthermore, these data can be used to support translation into the clinic of anti-MMDSC strategies in order to potentially enhance the effectiveness of immunotherapy in CRC.

\section{Materials and methods}

\section{Blood and tumour sample collection and patient inclusion and exclusion criteria}

Heparinized blood samples were obtained from patients with histologically confirmed colon carcinoma $(n=67)$ prior to surgery, following informed consent, at the University of Birmingham Hospitals Trust, UK. Fresh tumour samples $(n=41)$ or matched adjacent normal intestinal tissue $(n=27)$ from diagnostic surgery were collected and processed within $12 \mathrm{~h}$. Blood was also obtained from age-matched healthy donors at the University of Birmingham, $\mathrm{UK}(n=33)$. There was no lower or upper age limit for participation and both males and females were included. The only exclusion criteria that were used for patient sample collection were cancers in those patients undergoing emergency surgery and/or cancers arising on the background of known inflammatory bowel disease. Participants did not undergo randomization as this was irrelevant to our study.

\section{Flow cytometry analysis of whole blood and tumours}

Red blood cells were lysed using ammonium chloride solution according to manufacturer's instructions (Qiagen, Cat\# $1,045,722$ ) for $10 \mathrm{~min}$ at room temperature prior to antibody staining. Tumour and tissue samples were digested using Type II collagenase (Sigma; Cat\#C6885-100MG;) for three hours at $37{ }^{\circ} \mathrm{C}$, washed and re-suspended in RPMI $+10 \%$ FBS; R10\% (RPMI-1640 (Sigma-Aldrich; Cat\# R8758) with $10 \%$ heat-inactivated fetal bovine serum, glutamine (1X), sodium pyruvate (1X) and Penicillin-Streptomycin (RPMI 10\%=R10\%). Immune populations were identified by staining with anti-human antibodies: anti-CD33-APC (BioLegend Cat\# 303,408, RRID:AB_314352), anti-HLADR-PE (BD Biosciences Cat\# 555,812, RRID:AB_396146), anti-CD14-PE-Cyanine7 (Thermo Fisher Scientific Cat\# 25-0149-42, RRID:AB_1582276), anti-CD68-Alexa Fluor 488 (BioLegend Cat\# 333,812, RRID:AB_2074832), anti-CD163-Brilliant Violet 421 (BioLegend Cat\# 333,612, RRID:AB_2562463), anti-CD206-APC/Cyanine7 (BioLegend Cat\# 321,120, RRID:AB_2144930) and anti-CD15FITC (BioLegend Cat\# 301,904, RRID:AB_314196) antibodies on ice for $30 \mathrm{~min}$ in Flow Buffer consisting of $1 \mathrm{X}$ 
PBS (Sigma-Aldrich: P3813) and 2\%BSA (Sigma- Aldrich: 9048-46-8). Cells were acquired using a Cyan and CytoFLEX flow cytometers and analysed using FlowJo and CytoExpert2.2.

\section{Multi-spectral immunohistochemistry and multiplex staining}

Colorectal carcinoma sections, from diagnostic tumour biopsies $(n=5)$, were deparaffinised in Histoclear (National diagnostics) and ethanol, and rehydrated in $0.3 \%$ hydrogen peroxide for $15 \mathrm{~min}$. Antigen retrieval was performed in $10 \mathrm{mM}$ sodium citrate buffer ( $\mathrm{pH} \mathrm{6.0)}$ ) for $20 \mathrm{~min}$ in a microwave oven. Slides were cooled and washed prior to blocking in $5 \mathrm{X}$ caesin (Thermofisher) for $30 \mathrm{~min}$ at room temperature. Multi-colour immunofluorescent staining was carried out on the Leica Bond Max using an Opal ${ }^{\text {TM }}$ 7-colour fIHC kit (Perkin Elmer Cat\# NEL80100KT) and the following primary antibody fluorochrome combinations: CD3/Opal 520, CD14/Opal 570, HLA-DR/Opal 620 and CK (monoclonal mouse anti-human cytokeratin (concentrate) antibody clone AE1/AE3)/Opal 650. Staining was imaged with the Vectra Automated Quantitative Pathology Imaging System (Perkin Elmer) and 7-11 representative fields per case quantitatively analysed using Inform Advanced Image Analysis software v 2.3 (Perkin Elmer). Nearest Neighbour analysis performed using the $R$ programming language Version 3.5.1( $R$ Core Team (2018) https://www.R-project.org/.) in conjunction with the inForm Helper Functions $R$ package Version 0.1.2. (https://akoyabio.github.io/phenoptr/) and 'Tidyverse' $R$ package Version 1.2.1. (https://CRAN.R-project.org/packa ge=tidyverse).

\section{Blood and tumour cell isolation and sorting}

Peripheral blood mononuclear cells (PBMC) were isolated from the whole blood of patients or healthy donors following Lymphoprep (Stem Cell Technologies, Cat\# 07,851/07861) centrifugation. The $\mathrm{CD} 14^{+} \mathrm{PBMC}$ fraction was isolated by incubation with anti-CD14 microbeads (Miltenyi Biotech; Cat\# 130-050-201) and sorting using MACS LS separation columns (Miltenyi Biotech, Cat\# 130-042-401) according to manufacturer's instructions. Where indicated $\mathrm{CD}_{14}{ }^{+}$cells were then further isolated into HLA-DR ${ }^{+}$ and HLA-DR ${ }^{-}$fractions by a second sorting with HLADR microbeads (Miltenyi Biotech, Cat\# 130-046-101) and LS column separation. Cell purity was $>98 \%$ as confirmed by flow cytometry using anti-CD14-PE-Cyanine7,
anti-HLA-DR-PE or anti-CD3 (BD Biosciences Cat\# 555,335, RRID:AB_398591) antibodies.

The CD14- leukocyte population from healthy donors was used as responding $\mathrm{T}$ cells in the anti-CD3/CD28 antibody proliferation assays. Cell populations were similarly isolated from the collagenase digested tumours suspension using anti-CD14 MACS beads (CD14 ${ }^{+}$myeloid cells) or anti-CD326 EPCAM MACS beads (Miltenyi Biotech; Cat\# 130-061-101)(CD326 ${ }^{+}$tumour cells). Purity was confirmed by flow cytometry. No effect of collagenase on cell surface marker expression or cell viability was observed.

\section{Cell line authentication and validation and monocyte polarisation with TCM and cytokines}

To generate tumour conditioned media (TCM), CD326 ${ }^{+}$ sorted patients' tumour cells were first plated $\left(1 \times 10^{6}\right.$ cells $)$ and cultured for $48 \mathrm{~h}$. The conditioned media was removed and filtered prior to use. Colorectal cancer cell lines HT29 (ATCC ${ }^{\mathrm{R}}$ HTB-38 $^{\mathrm{TM}}$ ), HT55 (ATCC ${ }^{\mathrm{R}}$ HTB-55 ${ }^{\mathrm{TM}}$ ), and WiDr $\left(\mathrm{ATCC}^{\mathrm{R}} \mathrm{CCl}-218^{\mathrm{TM}}\right.$ ) were all freshly obtained from the ATCC collection to ensure full authentication and validation and tested negative for mycoplasma contamination and were similarly cultured in RPMI $+10 \%$ FBS, with penicillin-streptomycin. Sorted healthy donor $\mathrm{CD} 14^{+}$monocytes were plated in $\mathrm{R} 10 \%$ or with $100 \%$ of total volume TCM or $10 \mathrm{ng} / \mathrm{ml}$ of human recombinant cytokines (PeproTech: TGF- $\beta$ Cat\# 100-21-50; IL-6 Cat\# 200-06; IL-10 Cat\# 200-10; G-CSF Cat\# 500-P43; GM-CSF Cat\# 300-03 and VEGF Cat\# 100-20) in 24 well plates for $48 \mathrm{~h}$. These polarised monocytes were harvested, washed twice, and used as described below. Where indicated $\mathrm{CD} 14^{+}$cells $\left(1 \times 10^{6}\right.$ cells) were pre-treated for $1 \mathrm{~h}$ with TGF- $\beta$ receptor inhibitor (LY364947 [5 $\mu \mathrm{M}$ ]; TOCRIS Biotechne) followed culture in TCM or TGF- $\beta(10 \mathrm{ng} / \mathrm{ml})$ for $48 \mathrm{~h}$.

\section{T cell proliferation assay}

T cells $\left(2 \times 10^{5}\right)$ were cultured in 96 well flat bottom plates coated with anti-CD3 antibody $(3 \mu \mathrm{g} / \mathrm{ml})((\mathrm{eBio}-$ science, Thermo Fisher Scientific Cat\# 16-0037-85, RRID:AB_468855)) and anti-CD28 antibody $(2 \mu \mathrm{g} /$ ml) (Thermo Fisher Scientific Cat\# 16-0289-85, RRID:AB_468927), in $200 \mu 1 \mathrm{R} 10 \%$. The suppressive ability of sorted $\mathrm{CD} 14^{+}$cells from patients or from healthy donors following polarisation was assessed by co-culturing purified cells together with allogeneic $\mathrm{T}$ cells. Where indicated 
anti-IL-10 Receptor Antibody $(10 \mu \mathrm{g} / \mathrm{ml})(($ Thermo Fisher Scientific Cat\# 16-7108-85, RRID:AB_469229) (Isotype control, Rat IgG K Isotype, (Thermo Fisher Scientific Cat\# 16-4301-85, RRID:AB_470154) were added to cultures to inhibit IL-10 binding. Cells were incubated at $37^{\circ} \mathrm{C}, 5 \%$ $\mathrm{CO} 2$ for 4 days and then $1 \mu \mathrm{Ci} /$ well ${ }^{3} \mathrm{H}$-thymidine (Perkin Elmer Life Sciences, Beaconsfield, UK) was added for 12-16 h. ${ }^{3} \mathrm{H}$-thymidine incorporation was measured using a TopCount reader (Perkin Elmer). Data are expressed as a percentage of $\mathrm{T}$ cell proliferation driven by antibody costimulation in the presence of $\mathrm{CD} 14^{+}$cells, compared to $\mathrm{T}$ cell proliferation in the absence of suppressive cells (100\%).

\section{ELISA}

The concentration of cytokines within conditioned media of patient-derived $\mathrm{CD} 14^{+}$cells or TCM polarised healthy donor $\mathrm{CD} 14^{+}$or plasma was assessed using a LEGENDplex Multi-Analyte Flow Assay according to the manufacturers' instructions (LEGENDplex Human Proinflammation Panel 1 (13-plex) w/VbP; Biolegend; Cat\# 740,003, LEGENDplex HU Th Cytokine Panel 1 (13-plex) w/VbP; BioLegend Cat\#740,721, LEGENDplex ${ }^{\mathrm{TM}}$ HU Neuroinflammation Panel 1 (13-plex) w/VbP, BioLegend; Cat\#740,796).

\section{Western blotting}

Cells were extracted in lysis buffer (RIPA Buffer 1X (Thermo Scientific, Cat\# 89,900) containing PhosSTOP 1X (Roche, Cat\# 04,906,845,001) and Complete Inhibitor 1X (Roche, Cat\# 64,693,132,001)) and protein concentrations were assessed by Bradford protein concentration assay (Sigma-Aldrich, Cat\# 23,236). Samples were mixed with reducing SDS-PAGE sample buffer (4X Lamelli Sample (BioRad, Cat\#1,610,747) + 10\% $\beta$-Mercaptoethanol) and subjected to Western Blotting. Briefly, proteins separated by reducing SDS-PAGE, were trans-blotted onto Hybond $\mathrm{C}^{+}$nitrocellulose membranes by electrophoresis. The membranes were incubated for $1 \mathrm{~h}$ with blocking solution (5\% BSA in PBS-T(Tween 1\%)) to block the non-specific protein binding-site prior to incubation with primary antibodies, at recommended dilutions, for $16 \mathrm{~h}(\mathrm{ON})$ at $4{ }^{\circ} \mathrm{C}$. Membranes were then washed in PBS-T, incubated with secondary HRP-conjugated antibodies diluted in blocking solution and immuno-reactive species detected by chemiluminescence reaction (BioRad, Cat\#170-5061), according to manufacturer's instructions. The following antibodies has been used: Phospho-Smad2(Ser465/467)/Smad3(Ser423/425) (D27F4)(Cell Signalling Technology Cat\# 8828S, RRID:AB_2631089; Rabbit), Anti-SMAD2/3 (Cell Signalling Technology Cat\# 5678S, RRID:AB_10693547;
Rabbit), Phospho-STAT3(Tyr705) (D3A7) (Cell Signalling Technology Cat\# 9145S, RRID:AB_2491009; Rabbit), AntiSTA3(D1B2J) Cell Signalling Technology Cat\# 30,835, RRID:AB_2798995; Rabbit), Phospho-p38 MAPK(Thr180/ Tyr182) (3D7) (Cell Signalling Technology Cat\# 9215S, RRID:AB_331762; Rabbit), Anti-p-38 MAPK (Cell Signalling Technology Cat\# 9212S, RRID:AB_330713; Rabbit), Phospho-p44/42 MAPK (Cell Signalling Technology Cat\# 9101S, RRID:AB_331646; Rabbit), p-44/42 MARK (Cell Signalling Technology Cat\# 9102S, RRID:AB_330744; Rabbit), $\beta$-Actin (Cell Signalling Technology Cat\# 4970, RRID:AB_2223172; Rabbit); HRP-conjugated antirabbit IgG (Cell Signalling Technology Cat\# 7074S, RRID:AB_2099233).

\section{Statistical analysis}

All the data were analysed using Graph Pad Software (RRID-SCR_002798. A T test analysis was used to determine the statistical significance of the difference in unpaired and paired groups according with the experimental design. A $p$ values $<0.05$ were considered to represent statistically significant events. A linear regression analysis was used to quantify the relationship between two variables, using a 95\% confidence interval.

\section{Study approval}

In accordance with the Declaration of Helsinki, patient samples were obtained after written, informed consent prior to inclusion in the study. Regional Ethics Committee (REC Number 10/H0501/39) and local hospital trust research approval for the study were granted for the University of Birmingham Hospitals Trust.

\section{Results}

\section{Suppressive $\mathrm{CD}_{14}^{+}$cells are elevated in the tumours of CRC patients}

Although the presence of granulocytic MDSCs (G-MDSCs) have been well defined in colorectal cancer patients [14], the presence of monocytic MDSCs (M-MDSCs) within the tumour microenvironment is less clear. Dissociation of human colorectal cancers revealed a significant increase in the frequency of $\mathrm{CD}_{1} 4^{+}$cells in the tumour compared to matched non-cancerous tissue ( $p=0.005$; Fig. 1a). There was no increase in the proportion of circulating $\mathrm{CD} 14^{+}$ cells in the blood of patients compared to healthy donors (Fig. 1a). To examine the effect of these myeloid cells on $\mathrm{T}$ cells co-culture proliferation assays were performed. 
A

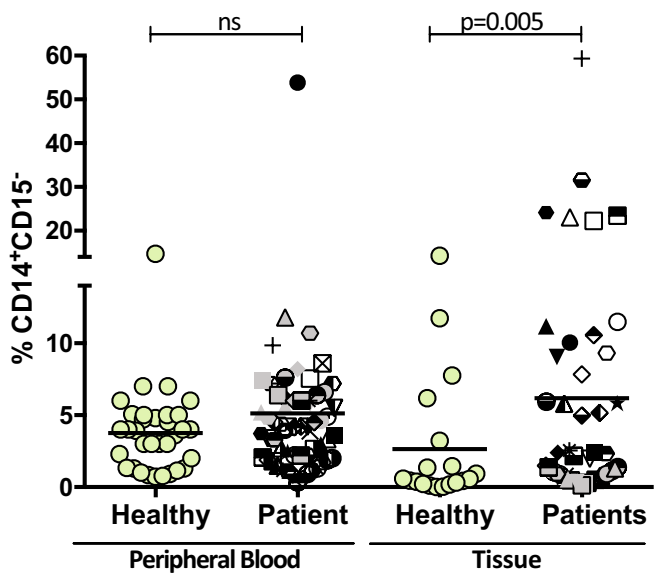

B

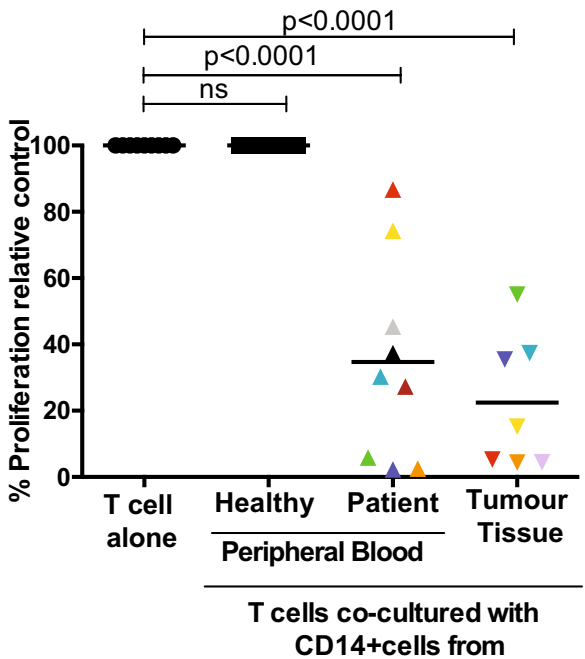

C
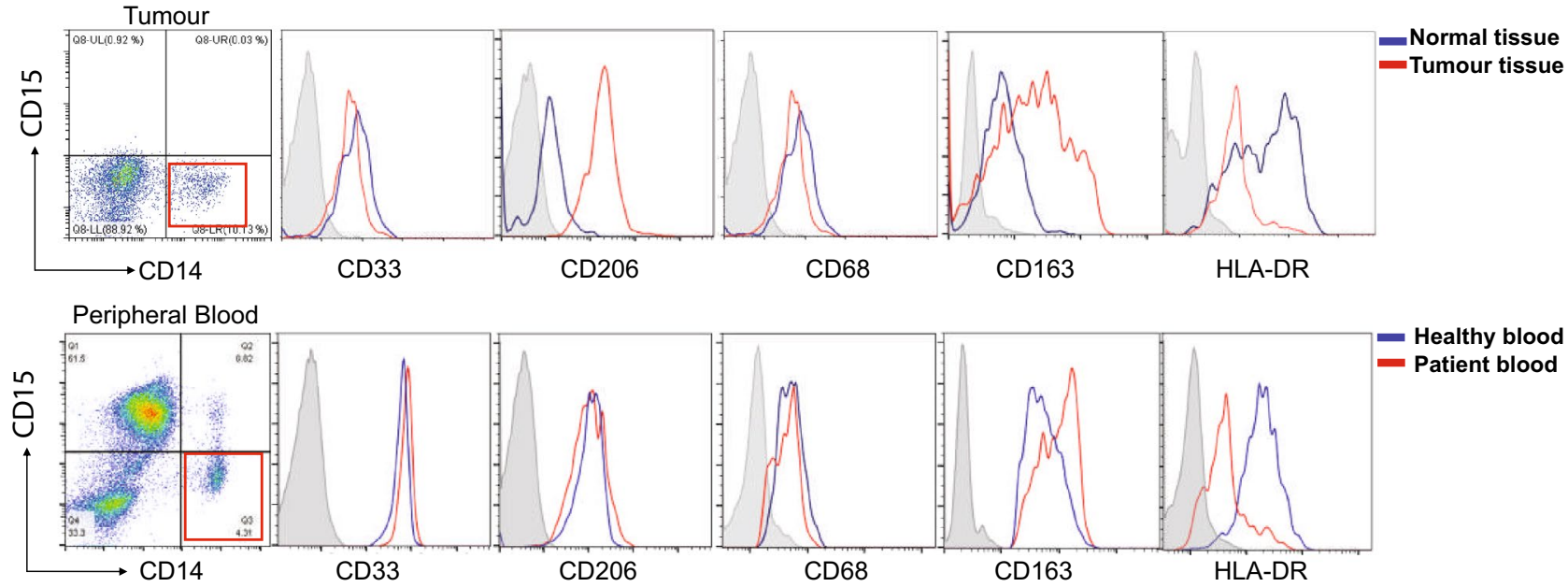

D

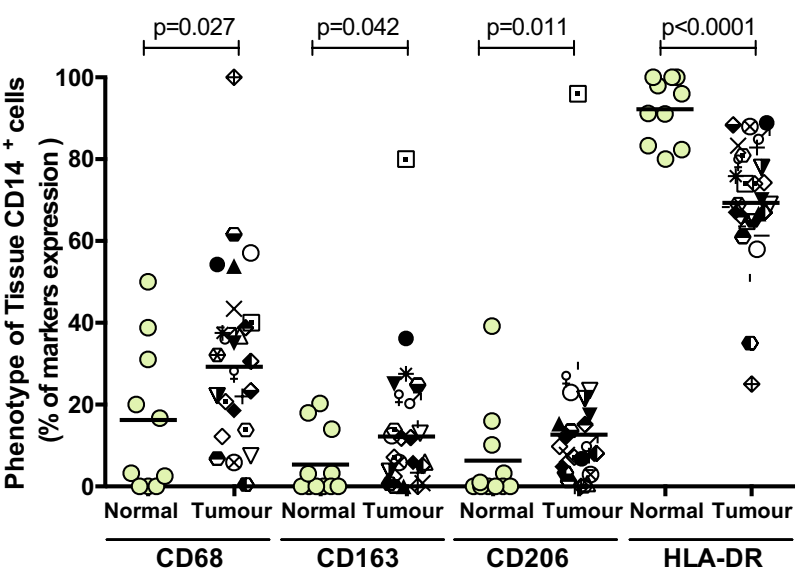

E

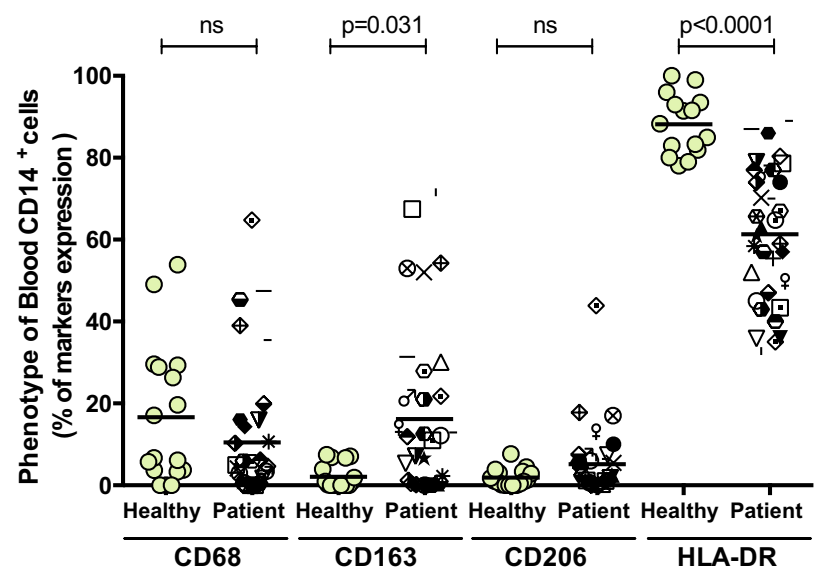

Fig. 1 CD14+ cells in the blood and tumour suppress peripheral blood leukocyte proliferation in CRC patients a Increased frequency of CD14+ monocytes staining in the peripheral blood $(n=53)$ and tissue $(n=18)$ of colorectal cancer samples and healthy control $(p=0.005)$. b Allogeneic $\mathrm{T}$ cell proliferation under anti-CD3/CD28 antibody stimulation is suppressed with the addition of CD14+ cells from tissue ( $\mathrm{n}=7$ ) and the blood $(n=9)$ of CRC patients, as measured by 3 H-Tymidine uptake, compared to CD14+cells from healthy donors $(p<0.0001)$. $\mathbf{c}$ Phenotypic analysis of CD14+ cells from blood and tissue of representative CRC patient. Flow analysis of CD14+ cells shows an increased expression of CD206,CD68, CD163 markers in the tumour tissue $\mathbf{d}$ and not in the blood $\mathbf{e}$ of CRC patients, instead and a significant down regulation of HLADR expression is measured in both the compartments compared healthy control 
Sorted CD $14^{+}$cells from colorectal tumours and from the peripheral blood strongly suppressed $\mathrm{T}$ cell proliferation $\left(p<0.0001\right.$, Fig. 1b). Healthy donor blood CD $14^{+}$cells had no effect on $\mathrm{T}$ cell proliferation (Fig. 1b).

\section{Tumoral and blood CD14 ${ }^{+}$HLA-DR $^{-}$cells are M-MDSCs and suppress T cell proliferation via IL-10 production}

The identification of immunosuppressive $\mathrm{CD} 14^{+}$cells in the blood and tumour of CRC patient raised the question as to whether these cells could be defined as M-MDSCs, which are characterized by reduced HLA-DR expression. The immunophenotype of $\mathrm{CD} 14^{+}$cells of CRC patients compared to healthy counterparts, show equivalent expression of myeloid marker CD33 (Supp Fig. 1A). CD14 cells from tumour tissue have higher expression of the macrophage markers CD68, CD206 and CD163 (Fig. 1c, d) but only CD163 was increased in patient blood CD14 ${ }^{+}$ cells (Fig. 1c, e). There was significant down-regulation of HLA-DR expression in both the blood and tissue of CRC patients (Fig. 1c-e). There was no correlation between the frequency of CD14 ${ }^{+} \mathrm{HLA}-\mathrm{DR}^{-}$cells in the blood and tumours of patients (Supp Fig. 1B).

To identify the geographical distribution of CD14+ cells, the intra-tumoral microenvironment was examined in-situ using multi-spectral immunohistochemistry (Fig. 2 and Supp Fig. 2). Staining identified that the majority of CD14 cells resided as a layer spanning the invasive margin of the tumours (yellow staining Fig. 2a panel (a) and Supp Fig. 2), and that the majority of these cells are HLA-DR ${ }^{-}$confirming the flow cytometry findings (Fig. 2a panel (b)). In contrast the tumour centres have relatively lower numbers of infiltrating $\mathrm{CD}_{14}{ }^{+}$cells (Fig. 2a panel (b) and (c)). The CD $14^{+}{ }^{H L A}-D^{-}$cells separate the tumour cells (red staining Fig. 2a panel (d)) from the $\mathrm{CD}^{+} \mathrm{T}$ cells (green staining Fig. 2a panel (d)), such that the majority of the $\mathrm{CD}^{+} \mathrm{T}$ cells are furthest from the malignant cells (Fig. 2b). Very few $\mathrm{T}$ cells infiltrate the tumour centre. Nearest neighbour analysis demonstrated that the median distance from the CD14 ${ }^{+}$ $\mathrm{HLA}_{-} \mathrm{DR}^{-}$cells to $\mathrm{CD}^{+}$cells at the invasive margin was either much less (Samples 1,3,4 and 5) or the same (Sample 2 ) as the distances from the CD14 ${ }^{+}$HLA-DR ${ }^{-}$cells to the $\mathrm{CD}^{+}$cells in the centre of the tumour. Thus, the invasive margin of colorectal cancers are enriched in $\mathrm{CD} 14^{+}$HLA$\mathrm{DR}^{-}$cells in close proximity to $\mathrm{T}$ cells.
To formally demonstrate that the M-MDSC population resided in the HLA-DR ${ }^{-}$fraction, $\mathrm{CD} 14^{+}$cells were sorted according to HLA-DR status and $\mathrm{T}$ cell proliferation assays performed. For both blood and cancer tissues the HLA$\mathrm{DR}^{-}$cells suppressed anti-CD3/CD28 stimulated $\mathrm{T}$ cells (Fig. 3a and Supp Fig. 3a, b). However, the HLA-DR ${ }^{+}$cells had no suppressive effect (Fig. 3a and Supp Fig. 3A and 3B).

M-MDSCs have been reported to suppress T cell proliferation by a number of mechanisms. The effect of inhibiting arginase 1 (ARG1) and nitric oxide synthase 2 was assessed using the small molecule inhibitors NOHA and L-NMMA, respectively, and was found not to rescue $\mathrm{T}$ cell proliferation inhibited by colorectal cancer patient's CD14+cells (Supp Fig. 3C). MDSCs may also suppress T cell responses through cytokine release. Previous studies have shown that in ovarian cancer $\mathrm{CD} 14^{+}$cells can suppress $\mathrm{T}$ cell proliferation via IL-10 [22]. To identify which cytokines were released, sorted cells from patients' tumours and blood were placed in culture and supernatants tested by ELISA. $\mathrm{CD} 14^{+}$cells from both tumours and blood released significantly more IL-10 (Fig. 3b) than those from healthy donors and HLA-DR ${ }^{-}$cells from colorectal patients are the main source of IL10 secretion (Fig. 3b). To determine whether the suppressive activity of the M-MDSCs in both tumours and blood might be IL-10 dependent, IL-10 receptor blocking antibody was added to $\mathrm{T}$ cell proliferation assays. Blockade of IL-10 signalling led to restoration of T cell proliferation in the presence of M-MDSCs from both the blood and tumours (Fig. 3c) of colorectal cancer patients. Thus, CRC M-MDSCs in CRC suppress T cell proliferation via IL-10 release.

\section{Colorectal cancer cells polarize tumour-associated monocytes to a M-MDSC phenotype}

Malignant cells from fresh patients' tumours were isolated by sorting for CD326(EPCAM) and placed in culture to generate tumour conditioned media. Tumour conditioned media (TCM) conferred on $\mathrm{CD} 14^{+}$cells from healthy donors the ability to release IL-10, whilst complete media had no effect (Fig. 3d). Furthermore, whilst incubation in complete media had no effect on the level of HLA-DR expression on healthy donor monocytes TCM from primary tumour cells and colon cell lines significantly reduced HLA-DR expression (Fig. 3e, f and Supp Fig. 4A). TCM significantly enhanced IL-10 production from the HLA-DR ${ }^{-}$fraction (Fig. $4 \mathrm{a}$ and 
Fig. 2 Tumour localization of CD14+ myeloid cells in colorectal cancer. A) Representative multispectral immunohistochemical staining of colorectal cancer section. The squares in the middle right panel and magnified in (a) indicates the area of colon analysed with higher magnification where arrows indicate an increase in magnification of the specified area upper squares, centre of tumour and lower squares, invasive margin: the magnified invasive margin image is shown in (d) and those of the tumour centre are shown in (b and c). CD14: Yellow; HLA-DR: Magenta; CD3: Cyan/green; CK:Red; nuclei: Blue. B) Frequency of CD14+ cells as a percentage of total cells in colorectal cancer tissue at the tumour centre and invasive margins, the percentage of DR-CD14+ cells and the distance of DR-CD14+ cells to $\mathrm{CD} 3+$ cells as determined by VECTRA spectral analysis $(\mathrm{n}=5)$

\section{A}
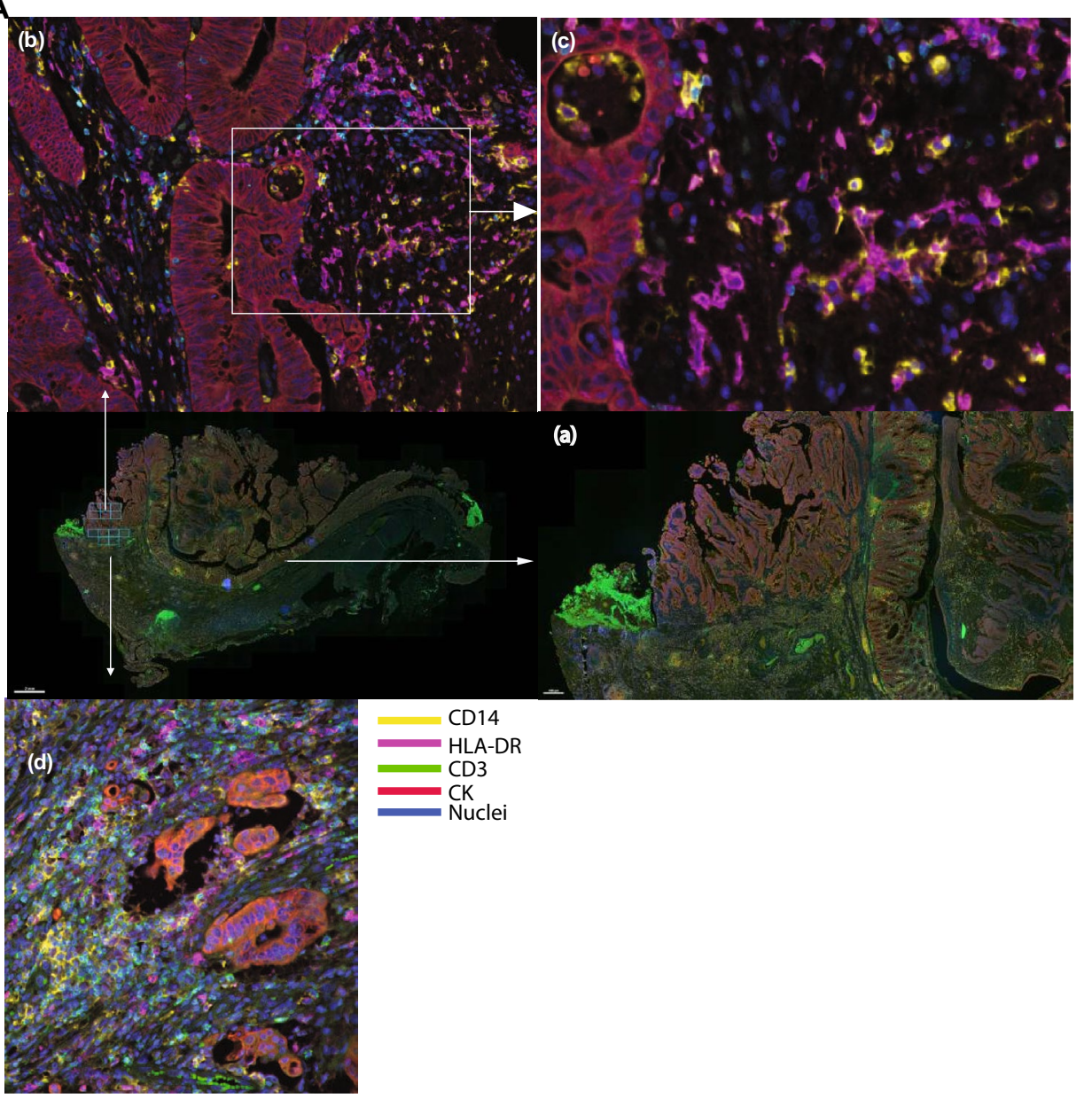

B

\begin{tabular}{|l|c|c|c|c|c|}
\hline & Sample 1 & Sample 2 & Sample 3 & Sample 4 & Sample 5 \\
\hline $\begin{array}{l}\text { CD14 \% } \\
\text { CENTRE }\end{array}$ & 6.11 & 2.20 & 6.17 & 3.46 & 1.18 \\
\hline $\begin{array}{l}\text { CD14\% } \\
\text { Invasive Margin }\end{array}$ & 16.51 & 10.10 & 6.79 & 4.96 & 8.11 \\
\hline $\begin{array}{l}\text { \%HLADR on CD14 } \\
\text { CENTRE }\end{array}$ & 58.08 & 71.66 & 28.57 & 43.06 & 83.11 \\
\hline $\begin{array}{l}\text { \%HLADR on CD14 } \\
\text { Invasive Margin }\end{array}$ & 75.25 & 60.05 & 61.54 & 51.1 & 81.52 \\
\hline $\begin{array}{l}\text { Distance of HLADR } \\
\text { CD14 to CD3 } \\
\text { CENTRE }\end{array}$ & 52.2 & 14.2 & 116.6 & 31.1 & 51.2 \\
\hline $\begin{array}{l}\text { Distance of HLADR } \\
\text { CD14 to CD3 } \\
\text { Invasive Margin }\end{array}$ & 22.7 & 15.6 & 32.4 & 12.5 & 16.7 \\
\hline
\end{tabular}



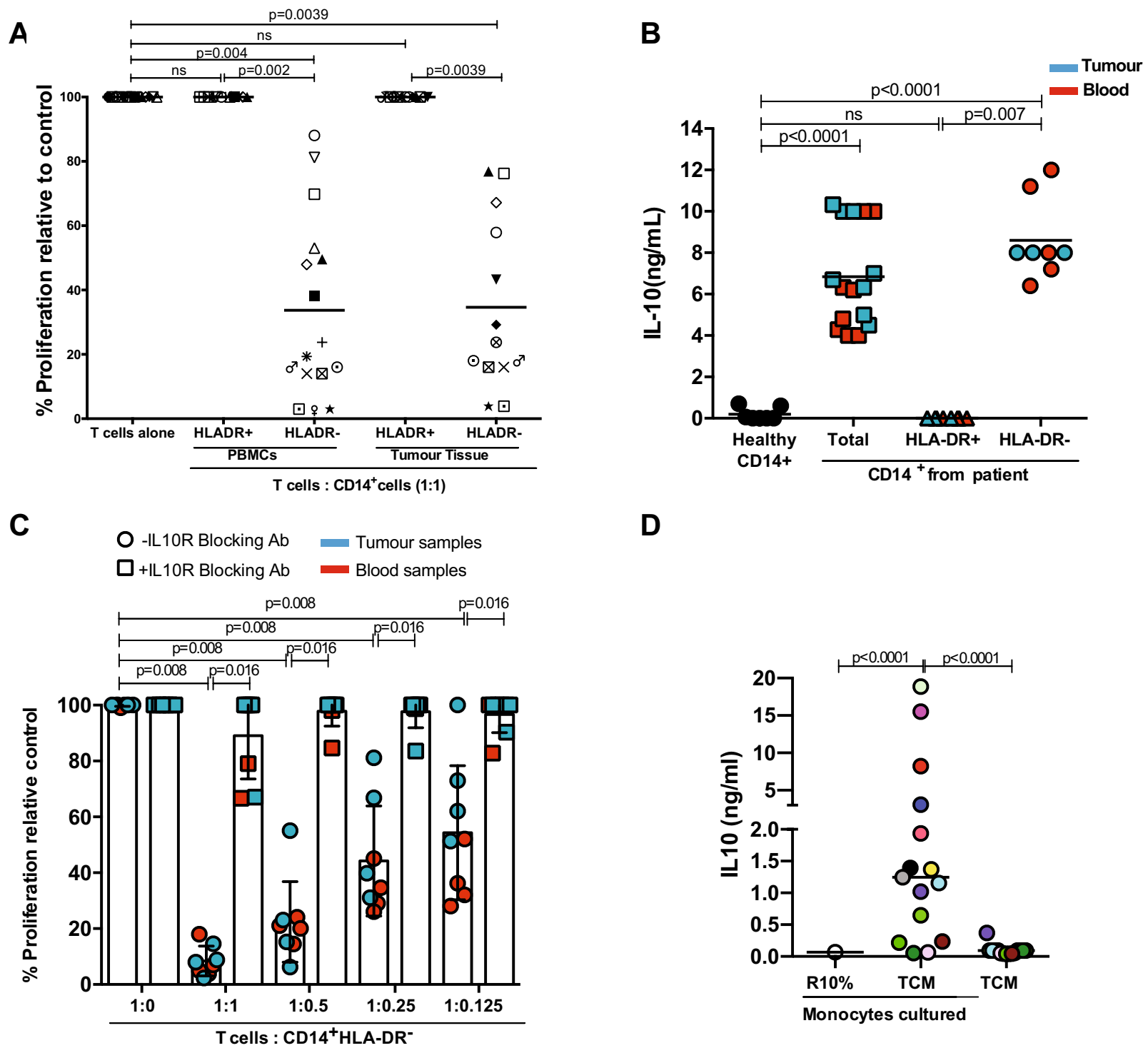

D

E
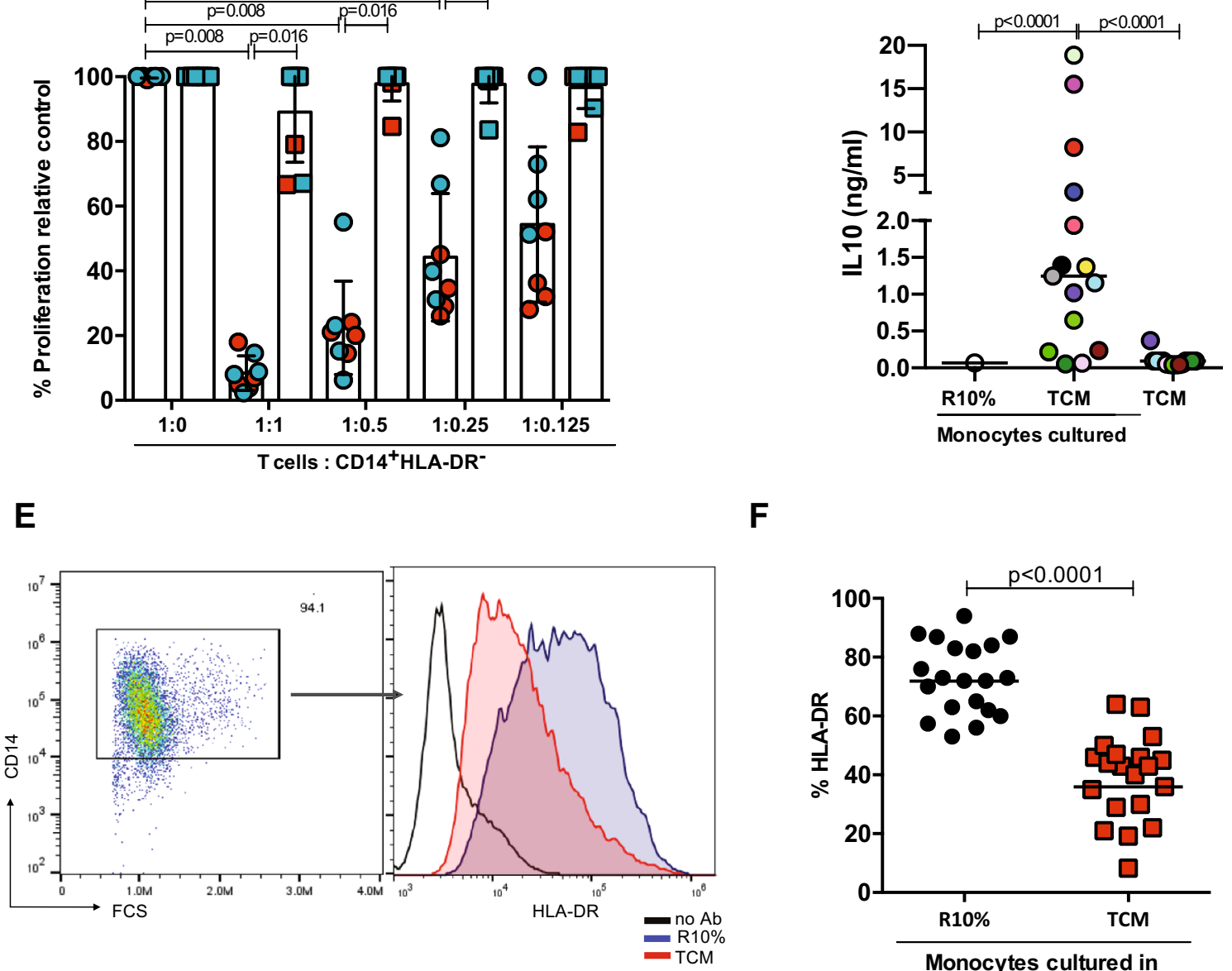

F

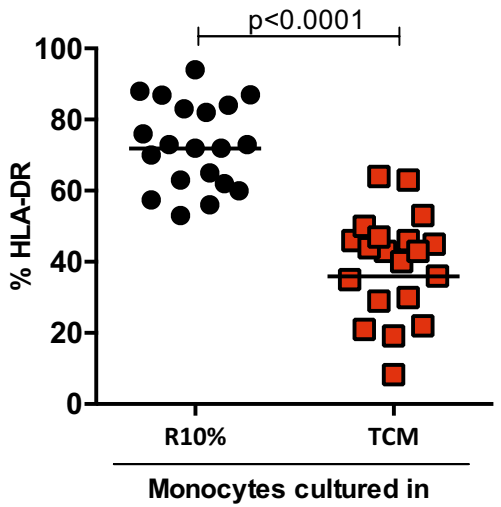


4Fig. 3 CD14+HLA-DR- cells are the major immunosuppressive cells in CRC. a Allogeneic T cell proliferation under anti-CD3/CD28 antibody stimulation is suppressed with the addition of CD14+HLA-DRcells from the blood $(n=16)$ and the tissue $(n=13)$ of CRC patients, as measured by 3 HTymidine uptake. The CD14+HLA-DR+ population is not suppressive. The 1:1 ratio of T cells:CD14+HLA-DR- cells is shown. Each colour represents a CRC patient. b Significantly higher level of IL-10 was detected by ELISA in the supernatant of CD14+ (blood samples $n=8$, tumour tissue $n=8$ )and CD14+HLA-DR- cells (blood samples $n=5$, tumour tissue $n=3$ ) compared healthy control. c IL-10 receptor blocking antibody $(10 \mu \mathrm{g} / \mathrm{ml})$ inhibits the suppressive activity of CD14+HLA-DR- cells of CRC patients restoring T cell proliferation $(n=10)$. d Colorectal tumour conditioned media (TCMs, $n=15$ )drive the release of IL10 from healthy monocytes after $48 \mathrm{~h}$ incubation. e A representative histogram of HLA-DR expression on monocytes after $48 \mathrm{~h}$ incubation with TCM. f Down regulation of HLA-DR on monocytes cultured with 20 TCMs

Supp Fig. 4B). Blockade with anti-IL-10 receptor antibody restored $\mathrm{T}$ cell proliferation to different extents that had been suppressed by TCM polarized CD $14^{+}$cells (Fig. 4b).Thus, the TCM of colorectal cancer cells reduces monocyte HLADR expression and up-regulates IL-10 production which drives a $\mathrm{T}$ cell suppressive phenotype.

\section{TGF- $\beta$ from colorectal tumour cells drives M-MDSC generation}

To identify the colorectal tumour factor(s) which mediates the polarization of M-MDSCs, tumour-conditioned media were analysed for cytokines by ELISA. A number of potential molecules were highly expressed including IL-10, G-GSF, IL-6, VEGF and TGF- $\beta$ (Fig. $4 c$ and Supp Fig. 4D) and these also accumulated in the plasma of CRC patients (Fig. 4d and Supp Fig. 4E). Culture of healthy donor monocytes with individual cytokines identified above showed that only TGF- $\beta$ led to a significant down-regulation of HLADR (Fig. 4e, f and Supp Fig. 5A). The HLA-DR- fractions obtained following TGF- $\beta$ treatment were associated with stronger immunosuppressive activity (Fig. 5a).

TGF- $\beta$ superfamily ligands control many fundamental aspects of cellular behaviour including cell proliferation and survival. This cytokine binds to a type I and II receptor, expressed on different cancer cells and myeloid cells, initiating intracellular signals with phosphorylation of SMAD protein and subsequently phosphorylation of STAT3 to regulate cell migration and invasion [23]. To confirm the intracellular pathway regulated by TGF- $\beta$, healthy donors $\mathrm{CD} 14^{+}$ cells were treated with TGF- $\beta$ and subsequently the HLA$\mathrm{DR}^{-}$and HLA-DR ${ }^{+}$fractions were enriched by sorting. No difference in the phosphorylation of p38 and ERK proteins were seen between HLA-DR ${ }^{-}$and HLA-DR ${ }^{+}$CD14 cells by Western blotting (Supp Fig. 5B). However, TGF- $\beta$ treatment increased the phosphorylation of SMAD and STAT3 protein, particularly in HLA-DR ${ }^{-}$cells (Fig. 5b). Treatment of CD14+ cells with TGF- $\beta$ induced IL-10 release (Supp Fig. 5C). Finally, blockade with an anti-TGF- $\beta$ receptor inhibitor interfered with the HLA-DR down-regulation on CD $14^{+}$cells treated with TGF- $\beta$ and TCMs (Fig. 5c, d, Supp Fig. 5D), with IL10 release (Fig. 5e), and with suppressive activity (Fig. 5f, Supp Fig. 5E). Thus, TGF- $\beta$ released by CRC cells causes activation of STAT3 and drives the production of M-MDSCs.

\section{Discussion}

We show here that M-MDSCs in CRC tissue and in the blood of CRC patients strongly suppress $\mathrm{T}$ cell proliferation via the production of IL-10 and that TGF- $\beta$ released by CRC cells is responsible for the polarisation of monocytes to become HLA-DR ${ }^{-}$suppressors. We show that TGF- $\beta$ treatment increases $\mathrm{CD} 14^{+}$pSTAT3 particularly in HLA$\mathrm{DR}^{-}$cells. STAT3 mediates down-regulation of MHC class II on antigen presenting cells $[24,25]$ and IL-10 production by macrophages [25] Previous work shows that suppressive M-MDSCs in pancreatic cancer have down-regulation of miRNAs that bind and repress the STAT3 promoter, have enhanced expression of pSTAT3 and that STAT3 inhibition abrogates CD14+ suppressivity [26] CRC M-MDSCs are mainly localised at the invasive margin of the cancer in line with the monocyte and TGF- $\beta$ enrichment characteristic of consensus molecular subtype 4 , the molecular subtype associated with the invasive front $[27,28]$.

Our novel mechanistic findings describing the cross-talk between colorectal cancer cells, monocytes and $\mathrm{T}$ cells in the tumour microenvironment are supported by previous studies in other clinical and pre-clinical contexts analysing the impact of TGF- $\beta$ on monocytes and the role of monocyte-derived IL-10 in mediating immunosuppression. 
A

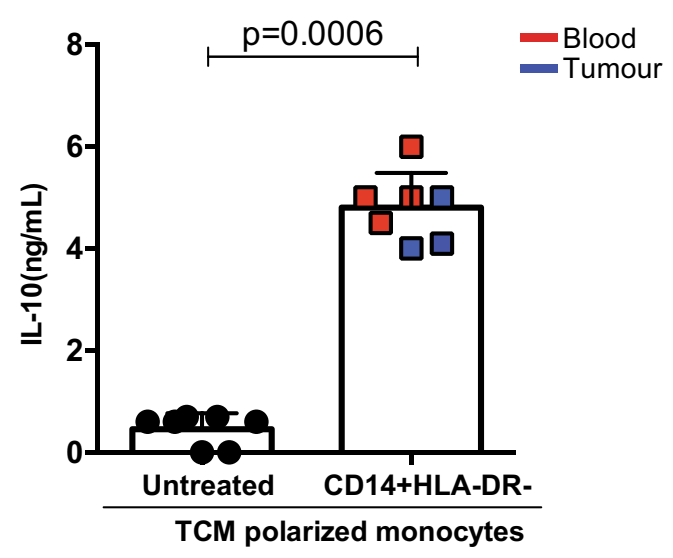

C

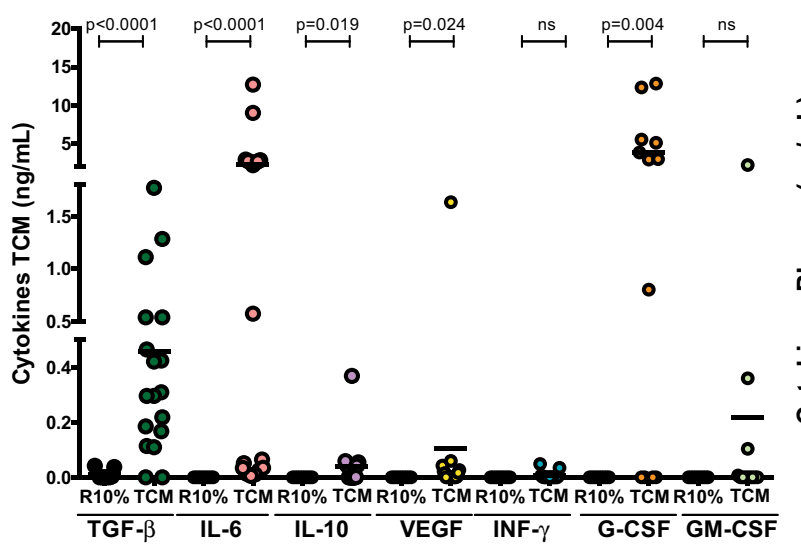

B

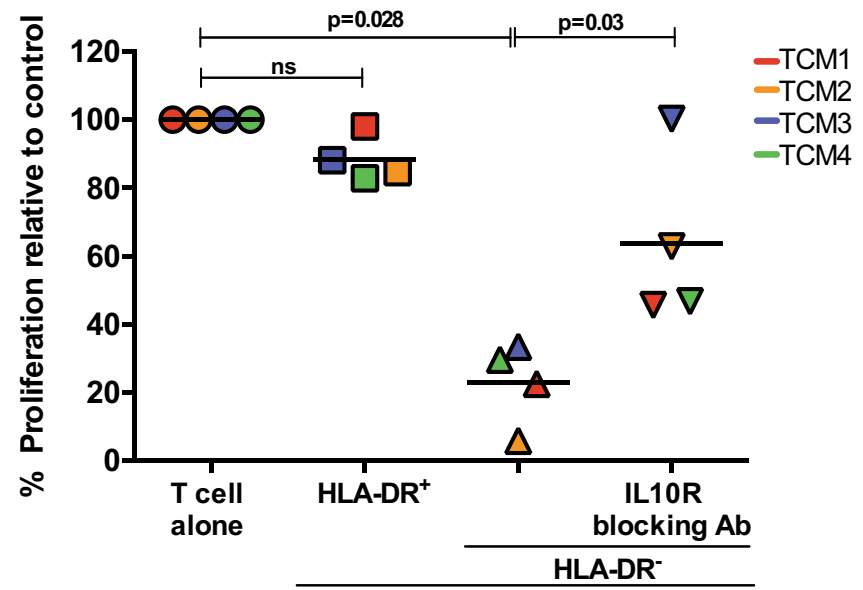

T cell co-cultured with TCM polarized monocytes

D

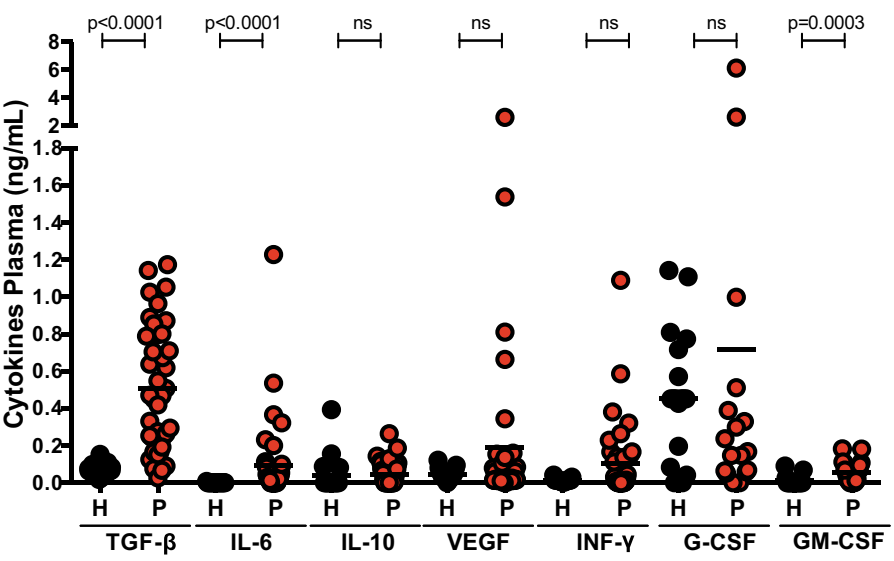

E

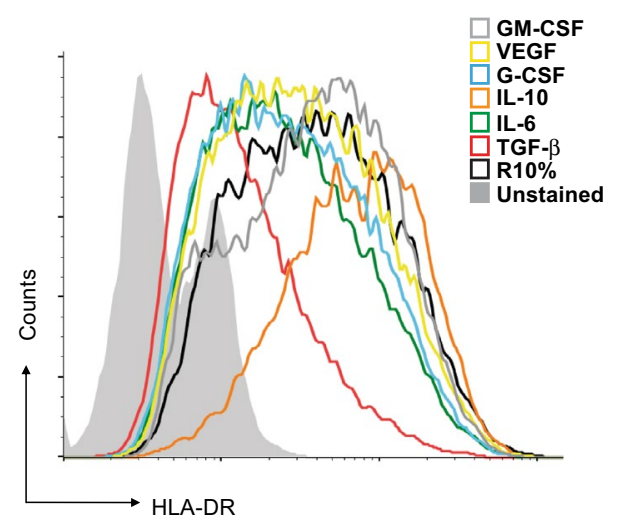

Fig. 4 Colorectal tumour conditioned media drives IL10 secretion. a Significantly higher level of IL-10 was detected by ELISA in the supernatant of CD14+HLA-DR- cells polarized by TCM (blood samples $n=4$, tumour tissue $n=3$ ) compared healthy control. b IL-10 receptor blocking antibody $(10 \mu \mathrm{g} / \mathrm{ml})$ inhibits the suppressive activity of TCMs polarized CD14+HLA-DR- cells restoring T cell proliferation $(n=4)$. Higher concentration of TGF- $\beta$ was measured by ELISA

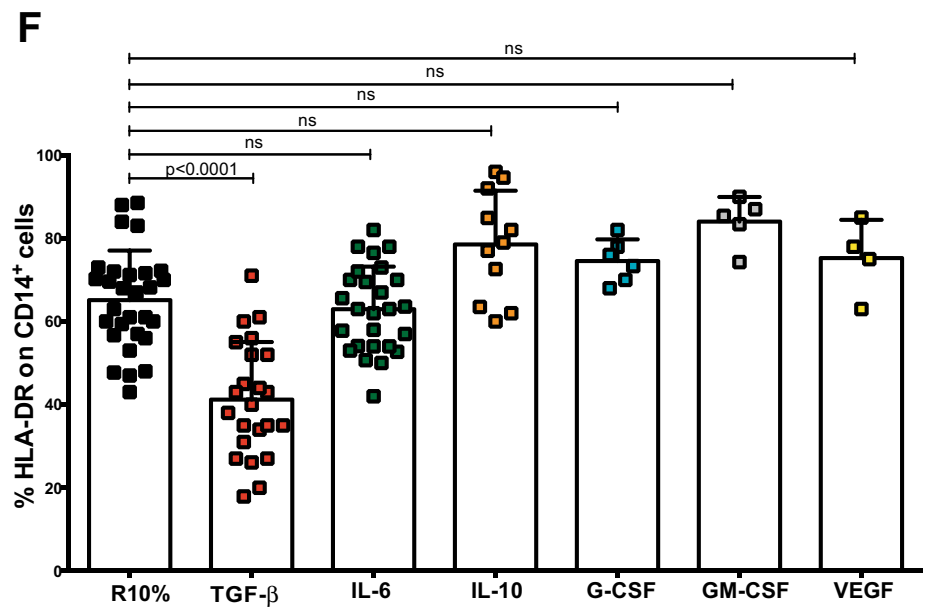

in TCM $(n=19)$ c and in the plasma $\mathbf{d}$ of colorectal patients $(n=39$ and healthy plasma $n=10$ ). e A representative histogram of HLA-DR expression on monocytes cultured with cytokines for $48 \mathrm{~h}$. f Down regulation of HLA-DR on monocytes cultured with cytokines for $48 \mathrm{~h}$ was observed by Flow analysis $(n=23$ TGF $\beta$, $n=26$ IL-6, $n=11$ IL-10, $\mathrm{n}=6 \mathrm{G}-\mathrm{CSF}, \mathrm{n}=5 \mathrm{GM}-\mathrm{CSF}$ and $\mathrm{n}=4 \mathrm{VEGF}$ ) 
IL-10 directly inhibits T cell proliferation [29]. Stimulated monocytes produce IL-10 [30] and monocyte-derived IL-10 suppresses both CD3-stimulated and alloantigen-stimulated $\mathrm{T}$ cell proliferation and potently reduces IFN $\gamma$ production [31], a cytokine essential for the activity of anti-PD1 therapy [32]. IL-10 transcripts are present in CD14 ${ }^{+}$leukocytes in the malignant ascites of ovarian cancer patients but not in the $\mathrm{CD}^{-} 4^{-}$fraction and are only present in the HLA$\mathrm{DR}^{-}$and not the HLA-DR ${ }^{+} \mathrm{CD} 14^{+}$population [33]. Whilst T cells co-cultured with autologous $\mathrm{CD} 14^{+} \mathrm{HLA}^{-\mathrm{DR}}{ }^{+}$cells produced IFN $\gamma$, no IFN $\gamma$ was produced when T cells were co-cultured with $\mathrm{CD} 14^{+}{ }^{\text {HLA-DR }}{ }^{-}$cells and the suppression of cytokine production could be reversed with IL-10 blockade. Co-incubation of autologous T cells with IL-10 producing monocytes inhibited their PHA-induced proliferation, and this inhibition could be reversed by the combination of anti-IL10R and anti-TGF- $\beta$ which was also found to be specifically expressed in the IL-10 producing CD14 ${ }^{+}$ cells. In the EL-4 tumour model IL-10 produced by macrophages increases in ascitic fluid in line with progression of disease and correlates with increased TGF- $\beta$ produced by the cancer cells [34]. There is a significant reduction in peritoneal IL-10 upon administration of anti-TGF- $\beta$. In vitro the enhanced IL-10 production by macrophages was abrogated by the administration of anti-TGF- $\beta$.

Recent data interrogating the TCGA show upregulation of TGF- $\beta 1$ in a number of cancers including CRC and this correlates with the markers expressed on M-MDSCs, CD14 and CD33, but not with the G-MDSC marker CD66b [35] (PMN-MDSCs are CD33 ${ }^{\mathrm{dim}}$ rather than the high expression seen on M-MDSCs [36]). TGF- $\beta$ activity co-localised with the presence of $\mathrm{CD} 11 \mathrm{~b}^{+}$cells [35]. TGF- $\beta$ maintains CD124 expression and enhances the viability of healthy donor $\mathrm{CD} 14^{+}$monocytes. The addition of TGF- $\beta$ to GM-CSF and IL- 6 to monocyte cultures increases the proportion of
$\mathrm{HLA}^{-\mathrm{DR}^{-}}$cells consistent with polarisation to an M-MDSC phenotype, enhances suppression of $\mathrm{CD}^{+} \mathrm{T}$ cell proliferation and function, decreases macrophage differentiation and increases the production of anti-inflammatory cytokines. TGF- $\beta$ blockade significantly reduces M-MDSC polarisation and increases the proportion of macrophage and HLA$\mathrm{DR}^{+}$DCs.

Our results are immediately translatable to the clinic. Given the fact that M-MDSCs appear to be the predominant MDSC population in CRC [21], that increase with treatment suggestive of a role in resistance [21] and are strongly immunosuppressive (data herein), abrogation of M-MDSC function may be a valuable adjunctive therapy both to immunotherapy and other standard of care therapies in CRC. Furthermore, given data demonstrating that M-MDSCs are the precursor of immune-suppressive TAMs [20], targeting of TAMs could be achieved by targeting the precursor M-MDSCs. We have recently reported on the impact of CD33 targeted therapeutics on MDSCs [37]. We confirmed that CD33 intensity was greater on M-MDSCs compared to PMN-MDSCs. Gemtuzumab ozogamicin (GO) is an antibody drug conjugate where the warhead calicheamicin is coupled to anti-CD33. We demonstrated that GO bound to patient $\mathrm{CD} 33^{+}$MDSCs and was rapidly internalised resulting in a dose-dependent decrease in viability, induction of apoptosis and the abrogation of the suppression of $\mathrm{T}$ cell proliferation [37].

The suppression of CAR-T proliferation by MDSCs against various targets was overcome by GO. We are about to initiate the GOTHAM trial of GO in solid cancers (principally CRC), HLH and MAS with a key focus on the impact of GO on the number and function of MDSCs. Given the essential role of M-MDSCs in immunosuppression and potentially in therapy resistance in CRC evaluation of its potential as an adjunctive therapy in $\mathrm{CRC}$ appears warranted. 
A

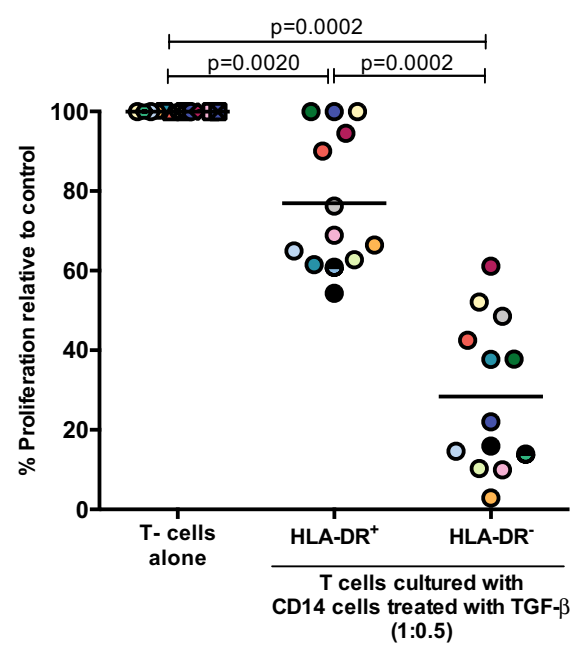

C

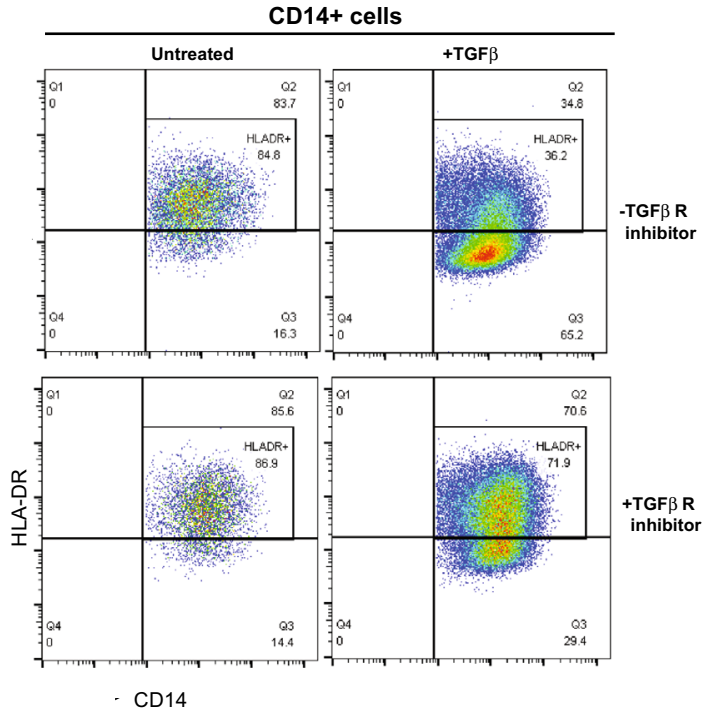

B

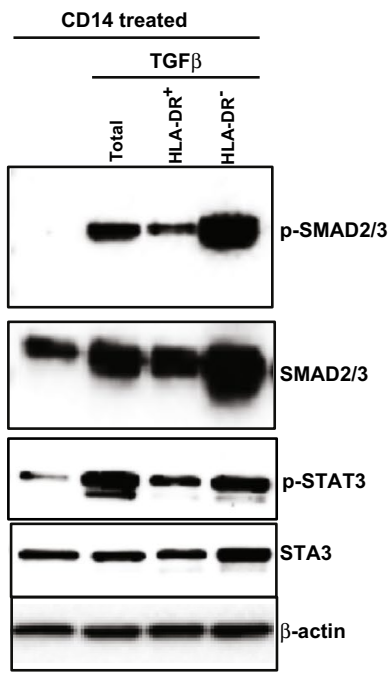

D
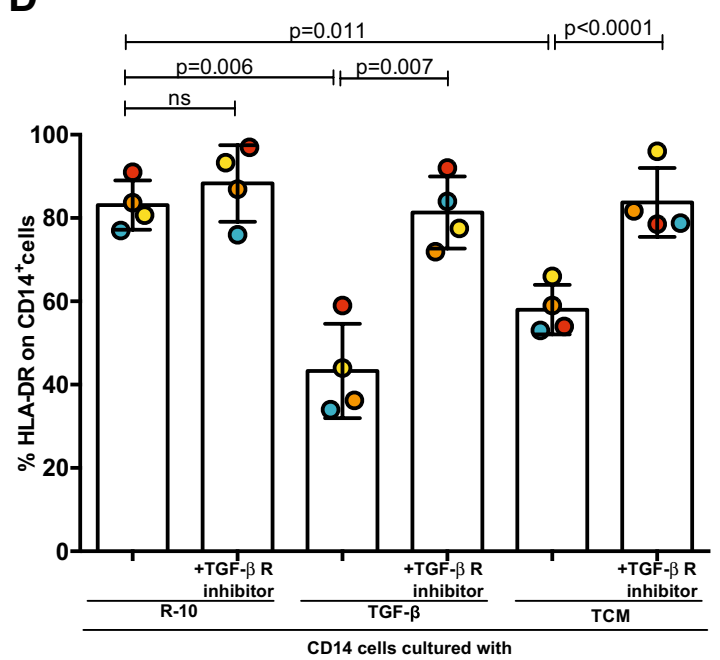

E

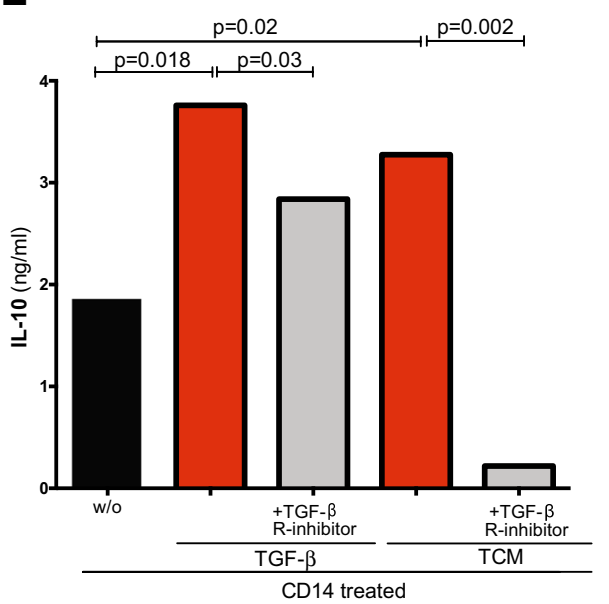

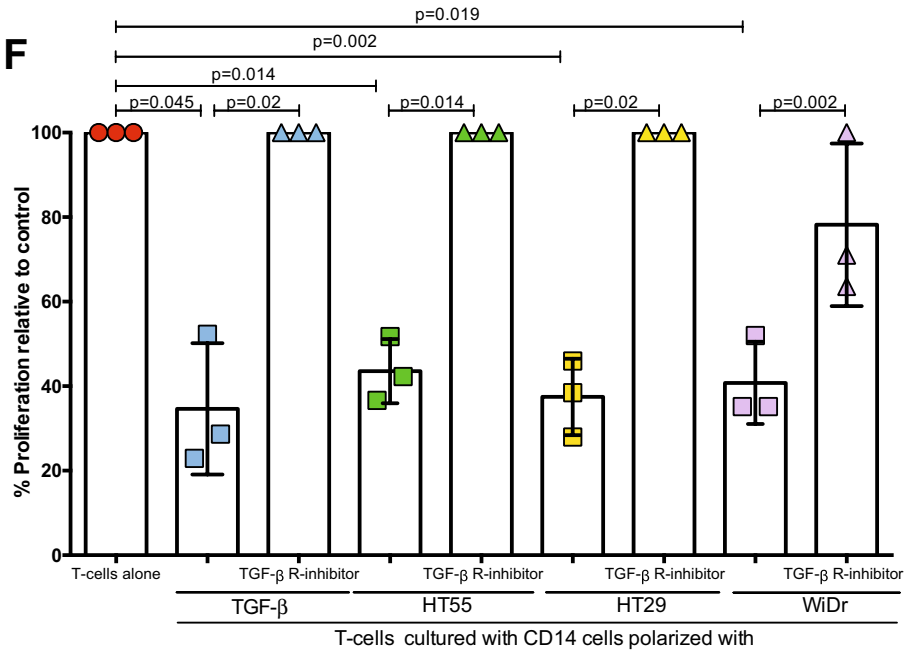


४Fig. 5 TGF- $\beta$ derived M-MDSC suppress T cell proliferation. a TGF- $\beta$ polarized CD14+HLA-DRcells suppress T-cell proliferation. Less suppressive activity has shown from TGF- $\beta$ polarized CD14+HLA-DR+ cells. The 1:0.5 ratio of T cells: myeloid cells shown $(n=13)$. b High expression of $p$-SMAD and p-STAT3 was detected by Western blot in the CD14+HLA-DR- cells polarized by TGF- $\beta$.Representative of 4 experiments. $\mathbf{c}$ and $\mathbf{d}$ TGF- $\beta$ receptor inhibitor inhibits the ability of TGF- $\beta$ and TCMs to down regulate HLA-DR on polarized monocytes $(n=4)$. e TGF- $\beta$ receptor inhibitor inhibits the release of IL-10 from TGF- $\beta$ and TCM polarized monocytes. Representative of 2 experiments. fTGF- $\beta$ receptor inhibitor inhibits the suppressive activity of CD14+HLA-DR- cells polarized with TGF- $\beta$ and CRC cell TCM $(n=3)$

Supplementary Information The online version contains supplementary material available at https://doi.org/10.1007/s00262-021-03081-5.

Author contributions Conceptualization: GM, FM and CdeS. Methodology: GM, FM, CdeS, LG, NR, RH. Formal analysis: GM, FM, CdeS, LG, NR, RH. Investigation: CdeS, LG, NR, RH. Resources: GM, FM and CdeS. Writing: GM, FM, CdeS, LG, NR. Supervision: GM, FM and CdeS. Funding acquisition: GM, FM and CdeS. All authors read and approved the final manuscript.

Funding We acknowledge the help of the Queen Elizabeth Hospital Birmingham Charity and the Birmingham CR UK Cancer Centre. GM acknowledges funding from DARO, University of Birmingham.

Data availability Source data will be made available in the event of acceptance for publication.

\section{Declarations}

Conflict of interest The authors have no disclosures and no competing interests in relation to this manuscript or work.

Consent for publication We the authors give full consent to $\mathrm{CII}$ for publication in the event of acceptance.

Ethical approval Regional Ethics Committee (REC Number 10/ H0501/39) and local hospital trust research approval for the study was granted for the University of Birmingham Hospitals Trust.

Informed consent In accordance with the Declaration of Helsinki, patient samples were obtained after written, informed consent prior to inclusion in the study.

Open Access This article is licensed under a Creative Commons Attribution 4.0 International License, which permits use, sharing, adaptation, distribution and reproduction in any medium or format, as long as you give appropriate credit to the original author(s) and the source, provide a link to the Creative Commons licence, and indicate if changes were made. The images or other third party material in this article are included in the article's Creative Commons licence, unless indicated otherwise in a credit line to the material. If material is not included in the article's Creative Commons licence and your intended use is not permitted by statutory regulation or exceeds the permitted use, you will need to obtain permission directly from the copyright holder. To view a copy of this licence, visit http://creativecommons.org/licenses/by/4.0/.

\section{References}

1. Bronte V, Brandau S, Chen SH, Colombo MP, Frey AB, Greten TF et al (2016) Recommendations for myeloid-derived suppressor cell nomenclature and characterization standards. Nat Comms $7: 12150$

2. http://www.cancerresearchuk.org/health-professional/cancer-stati stics/statistics-by-cancer-type/bowel-cancer

3. Kim K, Skora AD, Li Z, Liu Q, Tam AJ, Blosser RL et al (2014) Eradication of metastatic mouse cancers resistant to immune checkpoint blockade by suppression of myeloid-derived cells. Proc Natl Acad Sci U S A 111(32):11774-11779

4. Highfill SL, Cui Y, Giles AJ, Smith JP, Zhang H, Morse E et al (2014) Disruption of CXCR2-mediated MDSC tumor trafficking enhances anti-PD1 efficacy. Sci Transl Med 6(237):23ra7673

5. Duffy A, Zhao F, Haile L, Gamrekelashvili J, Fioravanti S, Ma C et al (2013) Comparative analysis of monocytic and granulocytic myeloid-derived suppressor cell subsets in patients with gastrointestinal malignancies. Cancer Immunol Immunother 62(2):299-307

6. Limagne E, Euvrard R, Thibaudin M, Rébé C, Derangère V, Chevriaux A et al (2016) Accumulation of MDSC and Th17 cells in patients with metastatic colorectal cancer predicts the efficacy of a FOLFOX-bevacizumab drug treatment regimen. Cancer Res 76(18):5241-5252

7. Tada K, Kitano S, Shoji H, Nishimura T, Shimada Y, Nagashima $\mathrm{K}$ et al (2016) Pretreatment immune status correlates with progression-free survival in chemotherapy-treated metastatic colorectal cancer patients. Cancer Immunol Res 4(7):592-599

8. Zhang B, Wang Z, Wu L, Zhang M, Li W, Ding J et al (2013) Circulating and tumor-infiltrating myeloid-derived suppressor cells in patients with colorectal carcinoma. PLoS One 8(2):e57114

9. Toor SM, Syed Khaja AS, El Salhat H, Bekdache O, Kanbar J, Jaloudi $\mathrm{M}$ et al (2016) Increased levels of circulating and tumor-infiltrating granulocytic myeloid cells in colorectal cancer patients. Front Immunol 7:560

10. Sun HL, Zhou X, Xue YF, Wang K, Shen YF, Mao JJ et al (2012) Increased frequency and clinical significance of myeloid-derived suppressor cells in human colorectal carcinoma. World J Gastroenterol 18(25):3303-3309

11. Ou Yang LY, Wu XJ, Ye SB, Zhang RX, Li ZL, Liao W et al (2015) Tumor-induced myeloid-derived suppressor cells promote tumor progression through oxidative metabolism in human colorectal cancer. J Transl Med 13:47

12. Yamamoto T, Kawada K, Itatani Y, Inamoto S, Okamura R, Iwamoto $\mathrm{M}$ et al (2017) Loss of SMAD4 promotes lung metastasis of colorectal cancer by accumulation of $\mathrm{CCR} 1^{+}$tumor-associated neutrophils through CCL15-CCR1 axis. Clin Cancer Res 23(3):833-844

13. Wu P, Wu D, Ni C, Ye J, Chen W, Hu G et al (2014) $\gamma \delta T 17$ cells promote the accumulation and expansion of myeloid-derived suppressor cells in human colorectal cancer. Immunity 40(5):785-800

14. Governa V, Trella E, Mele V, Tornillo L, Amicarella F, Cremonesi E et al (2017) The interplay between neutrophils and $\mathrm{CD}^{+} \mathrm{T}$ cells improves survival in human colorectal cancer. Clin Cancer Res 23(14):3847-3858

15. Amicarella F, Muraro MG, Hirt C, Cremonesi E, Padovan E, Mele $V$ et al (2017) Dual role of tumour-infiltrating T helper 17 cells in human colorectal cancer. Gut 66(4):692-704

16. Condamine T, Dominguez GA, Youn JI, Kossenkov AV, Mony S, Alicea-Torres K et al (2016) Lectin-type oxidized LDL receptor-1 distinguishes population of human polymorphonuclear 
myeloid-derived suppressor cells in cancer patients. Sci Immunol 1(2):aaf8943

17. Si Y, Merz SF, Jansen P, Wang B, Bruderek K, Altenhoff $P$ et al (2019) Multidimensional imaging provides evidence for downregulation of T cell effector function by MDSC in human cancer tissue. Sci Immunol 4(40):eaaw9159

18. Dolcetti L, Peranzoni E, Ugel S, Marigo I, Fernandez Gomez A, Mesa C et al (2010) Hierarchy of immunosuppressive strength among myeloid-derived suppressor cell subsets is determined by GM-CSF. Eur J Immunol 40(1):22-35

19. Haverkamp JM, Smith AM, Weinlich R, Dillon CP, Qualls JE, Neale G et al (2014) Myeloid-derived suppressor activity is mediated by monocytic lineages maintained by continuous inhibition of extrinsic and intrinsic death pathways. Immunity 41(6):947-959

20. Kwak T, Wang F, Deng H, Condamine T, Kumar V, Perego M et al (2020) Distinct populations of immune-suppressive macrophages differentiate from monocytic myeloid-derived suppressor cells in cancer. Cell Rep 33(13):108571

21. Karakasheva TA, Dominguez GA, Hashimoto A, Lin EW, Chiu $\mathrm{C}$, Sasser K et al (2018) CD $38^{+}$M-MDSC expansion characterizes a subset of advanced colorectal cancer patients. JCI Insight 3(6): 997022

22. Goyne HE, Stone PJ, Burnett AF, Cannon MJ (2014) Ovarian tumor ascites $\mathrm{CD} 14^{+}$cells suppress dendritic cell-activated $\mathrm{CD} 4^{+} \mathrm{T}$-cell responses through IL-10 secretion and indoleamine 2,3-dioxygenase. J Immunother 37(3):163-169

23. Liu RY, Zeng Y, Lei Z, Wang L, Yang H, Liu Z et al (2014) JAK/STAT3 signaling is required for TGF- $\beta$-induced epithelial-mesenchymal transition in lung cancer cells. Int J Oncol 44(5):1643-1651

24. Park SJ, Nakagawa T, Kitamura H, Atsumi T, Kamon H, Sawa S et al (2004) IL-6 regulates in vivo dendritic cell differentiation through STAT3 activation. J Immunol 173(6):3844-3854

25. Cheng F, Wang HW, Cuenca A, Huang M, Ghansah T, Brayer J et al (2003) A critical role for Stat 3 signaling in immune tolerance. Immunity 19(3):425-436

26. Trovato R, Fiore A, Sartori S, Canè S, Giugno R, Cascione L et al (2019) Immunosuppression by monocytic myeloid-derived suppressor cells in patients with pancreatic ductal carcinoma is orchestrated by STAT3. J Immunother Cancer 7(1):255

27. Becht E, de Reyniès A, Giraldo NA, Pilati C, Buttard B, Lacroix L et al (2016) Immune and stromal classification of colorectal cancer is associated with molecular subtypes and relevant for precision immunotherapy. Clin Cancer Res 22(16):4057-4066
28. Dunne PD, McArt DG, Bradley CA, O'Reilly PG, Barrett HL, Cummins $R$ et al (2016) Challenging the cancer molecular stratification dogma: intratumoral heterogeneity undermines consensus molecular subtypes and potential diagnostic value in colorectal cancer. Clin Cancer Res 22(16):4095-4104

29. Taga K, Mostowski H, Tosato G (1993) Human interleukin-10 can directly inhibit T-cell growth. Blood 81(11):2964-2971

30. de Waal MR, Haanen J, Spits H, Roncarolo MG, te Velde A, Figdor C et al (1991) Interleukin 10 (IL-10) and viral IL-10 strongly reduce antigen-specific human $\mathrm{T}$ cell proliferation by diminishing the antigen-presenting capacity of monocytes via downregulation of class II major histocompatibility complex expression. J Exp Med 174(4):915-924

31. Mielcarek M, Graf L, Johnson G, Torok-Storb B (1998) Production of interleukin-10 by granulocyte colony-stimulating factormobilized blood products: a mechanism for monocyte-mediated suppression of T-cell proliferation. Blood 92(1):215-222

32. Garris CS, Arlauckas SP, Kohler RH, Trefny MP, Garren S, Piot C et al (2018) Successful Anti-PD-1 cancer immunotherapy requires $\mathrm{T}$ cell-dendritic cell crosstalk involving the cytokines IFN- $\gamma$ and IL-12. Immunity 49(6):1148-1161.e7

33. Loercher AE, Nash MA, Kavanagh JJ, Platsoucas CD, Freedman RS (1999) Identification of an IL-10-producing HLA-DR-negative monocyte subset in the malignant ascites of patients with ovarian carcinoma that inhibits cytokine protein expression and proliferation of autologous T cells. J Immunol 163(11):6251-6260

34. Maeda H, Kuwahara H, Ichimura Y, Ohtsuki M, Kurakata S, Shiraishi A (1995) TGF-beta enhances macrophage ability to produce IL-10 in normal and tumor-bearing mice. J Immunol 155(10):4926-4932

35. Gonzalez-Junca A, Driscoll KE, Pellicciotta I, Du S, Lo CH, Roy $\mathrm{R}$ et al (2019) Autocrine TGFbeta is a survival factor for monocytes and drives immunosuppressive lineage commitment. Cancer Immunol Res 7(2):306-320

36. Marvel D, Gabrilovich DI (2015) Myeloid-derived suppressor cells in the tumor microenvironment: expect the unexpected. J Clin Invest 125(9):3356-3364

37. Fultang L, Panetti S, Ng M, Collins P, Graef S, Rizkalla N et al (2019) MDSC targeting with Gemtuzumab ozogamicin restores T cell immunity and immunotherapy against cancers. EBioMedicine $47: 235-246$

Publisher's Note Springer Nature remains neutral with regard to jurisdictional claims in published maps and institutional affiliations. 